\title{
Incentivizing access to family planning in Senegal via the informed push model
}

\author{
Leah Hasselback*, Babacar Gueye, Oumy Ndao, Soussaba Kanoute Ndour, Carol Cissé \\ From The 2nd People that Deliver (2nd PtD) Global Conference on Human Resources in Supply Chain \\ Management \\ Copenhagen, Denmark. 29-30 October 2014
}

\section{Background}

In Senegal, the absence of a well-functioning family planning (FP) product supply chain has acted as a significant supply-side barrier and contributed to Senegal's low contraceptive prevalence rate (CPR) (12.3\% in 2010) and high unmet need for FP among married women (29\%). Recurrent FP product stockouts at nearly $80 \%$ of public service delivery points (SDPs) continue to hinder the government's ability to achieve its goal of doubling CPR to $27 \%$ by 2015 .

\section{Method}

In 2012, IntraHealth International conducted a pilot of the informed push model (IPM) in 2 Senegalese regions to improve family planning product distribution. IPM, a lastmile distribution mechanism, moves FP products monthly from national pharmacy depots to health facilities via dedicated private logistics professionals. By utilizing task shifting, IPM reduces stockouts, which allows health workers to focus on health service provision and client satisfaction. The initiative is currently being expanded nationally.

\section{Results}

IPM immediately reduced and maintained stockout levels below $2 \%$ throughout the six-month pilot period. In target districts, contraceptive consumption increased by $38 \%$ and key logistics data reporting rose dramatically from $0 \%$ to $100 \%$. As IPM is being scaled up, health workers in the eight regions already utilizing the model have described it as a "revolution." At the health facility level, clients are benefitting from a constant supply of FP products and increased focus on provider-client interactions, resulting in more satisfaction with FP services received. Providers have also expressed greater job satisfaction, improved work flow, and better-quality reporting of data.

\section{Discussion}

Improvements in the FP commodity supply chain have the potential to boost health worker retention, improve client satisfaction, and increase women's access to contraceptives. With IPM, the logistics management burden is shifted from health workers to dedicated logistics professionals, leaving more time for providers to focus on service delivery quality. The model reintroduces a cost recovery system, which makes funds available so providers can ensure that clients have access to the methods they want. IPM also strengthens the supervision system by providing health workers with the opportunity to clarify their roles and responsibilities and improve workflow at the facility level.

\section{Lessons learned}

Shifting non-medical tasks from health providers to logistics professionals improves the service quality and provides women with a constant supply of family planning products. IPM strengthens public-private partnerships while incentivizing all parties to ensure that facilities and communities have access to family planning products.

Published: 17 December 2014

doi:10.1186/2052-3211-7-S1-012

Cite this article as: Hasselback et al.: Incentivizing access to family

planning in Senegal via the informed push model. Journal of

Pharmaceutical Policy and Practice 2014 7(Suppl 1):012.

\footnotetext{
* Correspondence: Ihasselback@intrahealth.org IntraHealth International, Washington DC, USA
} 